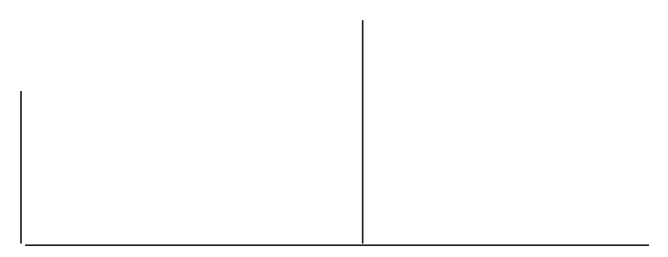

Rev. Latinoam. Psicopat. Fund., X, 3, 422-437

\title{
Demanda y transferencia en la psicosis. Puntualizaciones a partir de un fragmento clínico
}

\author{
Ada Jimena García Menéndez
}

\begin{abstract}
Este trabajo propone algunas consideraciones respecto de la especificidad de la demanda y la transferencia en la psicosis. Para ilustrar estas reflexiones teóricas, se presenta un fragmento de un caso clínico, dividido en tres momentos fundamentales que revelan diferentes modalidades de funcionamiento psíquico. Inicialmente, predominan las alucinaciones y las vivencias de fragmentación, ambas enigmáticas para el sujeto. Posteriormente, el paciente estructura un delirio místico que da cuenta de su filiación simbólica. En un tercer momento, se analizan las producciones pictóricas y oníricas, que permiten al sujeto un movimiento de historización y cierta estabilización.
\end{abstract}

Palabras claves: Demanda, transferencia, psicosis, alucinación, delirio 


\section{Consideraciones previas}

En este trabajo, a partir de la presentación de un fragmento clínico, intentaremos reflexionar acerca de la especificidad de la demanda y la transferencia en las psicosis.

La clínica psicoanalítica implica un distanciamiento respecto de todo enfoque deficitario de la psicosis. El psicoanálisis se resiste a pensar a la esquizofrenia o paranoia en términos negativos de déficit o disociación, por considerar que la división, la esquicia, nos parasita por el sólo hecho de que desconocemos nuestro deseo inconciente. Para Freud, la alucinación, lejos de ser un fenómeno deficitario, tiene un sentido, está ligada a la historia del sujeto (1893-1895) y es restitutiva (1924). En efecto, Freud (1911) apuesta a la producción subjetiva al establecer la función del delirio en tanto curativo. Por su parte, Lacan (1958), fiel a esta concepción, aborda la cuestión de un tratamiento posible a partir del trabajo que el psicótico puede hacer con aquello que, forcluído de lo simbólico, retorna en lo real. En este sentido, partimos de la convicción de que el acto analítico puede tener incidencia sobre el auto-tratamiento de lo real que supone el trabajo de la psicosis. La fórmula "no retroceder ante la psicosis" alude a que toda demanda de análisis debe ser alojada, independientemente de quien la enuncie. Si bien la demanda no 


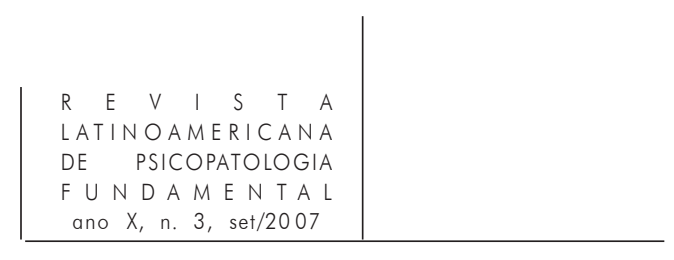

debe ser remitida a priori a una estructura clínica, podemos pensar que la demanda y la transferencia del psicótico ${ }^{1}$ plantean ciertas especificidades que es preciso tener en cuenta para ajustar nuestra respuesta.

El presente fragmento corresponde a un año de trabajo con Luciano, de 17 años. La división de la exposición en tres momentos responde a la intención de ordenar el material y de hacer énfasis en ciertos movimientos fundamentales del tratamiento. Sin embargo, la conceptualización de la temporalidad en psicoanálisis excluye las categorías de linealidad y progreso; de modo que, si bien en estos distintos momentos predominan ciertas modalidades de funcionamiento psíquico, no por esto los pensamos como etapas graduales de evolución del tratamiento.

\section{Primer momento: desencadenamiento, fenómeno elemental y vacío enigmático de la significación}

Comienzo mi trabajo con Luciano en un Servicio de Salud Mental público a partir de un pedido de su padre. Carlos, en una entrevista con los terapeutas de su esposa (paciente psicótica con recurrentes internaciones), refiere que Luciano, el tercero de sus cuatro hijos, ${ }^{2}$ está "raro", que no duerme, que habla solo.

En nuestra primera entrevista Luciano permanece callado. Mira por la ventana, sus frases son vagas, interrumpidas. Resulta difícil establecer contacto con él, parece estar absorto frente a la emergencia de fenómenos alucinatorios. Dice ver y escuchar muchas cosas, "el toro, en círculos, bocinas, un tren en mi cabeza. Me atormenta". ${ }^{3}$ Le propongo ayudarlo con lo que lo atormenta, acepta, y comenzamos a trabajar diariamente. Durante el período de crisis, trabajamos en equipo con una psiquiatra que le prescribe medicación neuroléptica.

Durante este primer tiempo, Luciano responde pasivamente a las preguntas. Los fenómenos a los que se refiere pueden ser analizados según dos vectores. Por un lado, se percibe el acoso de fenómenos alucinatorios elementales (un toro que da vueltas, un reloj, una bocina). Por el otro, constatamos fenómenos relativos a la fragmentación del cuerpo, acompañados de una vivencia de extrañeza y en un registro notablemente concreto: "me pica el cerebro del lado de adentro",

1. Tratándose de un tema que ha resultado controversial, partimos de la idea de que existe una transferencia psicótica, una modalidad de la transferencia específica de la psicosis. Cf. Allouch (1986).

2. La pareja tiene 4 hijos, una mujer de 26 años, un varón de 23, Luciano, y otra mujer de 16 años.

3. Para facilitar la lectura, citamos en itálicas el texto del paciente, y entre paréntesis las intervenciones del analista. 


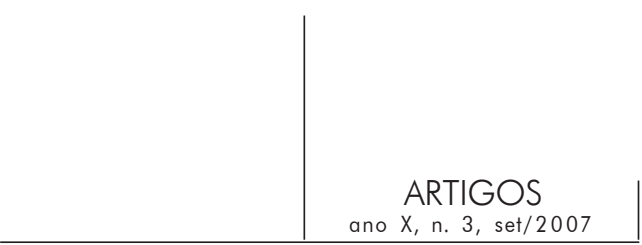

"estoy cansado, se me duerme el alma”, "estoy nervioso, se me rompió algún nervio de la cabeza". No queda claro si estos fenómenos de fragmentación corporal se reconducen a alucinaciones cenestésicas; de cualquier modo, es evidente que el cuerpo está comprometido en el Goce invasor que irrumpe. Permanece toda la noche despierto, no consigue dormir.

Curiosamente, Luciano no plantea ninguna hipótesis respecto de estas experiencias, ni puede precisar desde cuándo las padece. Por el contrario, parece experimentar, perplejo, el vacío enigmático de la significación (Soler, 2002). En este contexto las operaciones analíticas se circunscriben a una apelación al sujeto a tomar la palabra, en tres direcciones.

En primer lugar, se le propone la regla fundamental. Incluso cuando nada hacía pensar que respondería a esta apelación, le sugiero que me hable de todo lo que se le ocurra: sus pensamientos, recuerdos, sueños. Aunque no haya intenciones de instaurar un dispositivo analítico clásico, aún así consideramos que esta invitación a la palabra es vital para cualquier intervención analítica con un sujeto, neurótico o no.

En segundo lugar, intentamos circunscribir cuestiones relativas al desencadenamiento. Trabajosamente, se puede establecer que un año antes comenzó a sentirse "raro" y tuvo que dejar la escuela. "Era raro ese año, no me gustó ¿Vio que es difícil estudiar? Fue un peso muy grande. Y no me llevaba bien con nadie. Me sentaba atrás, y ellos se reían. De un año a otro fue un cambio raro, cambié la forma de ser". Situamos al desencadenamiento como momento de confrontación con una contingencia que deja al sujeto sin recursos. Para Lacan (1956), el desencadenamiento consiste en el encuentro con un enigma, en "la emergencia en la realidad de una significación enorme que parece una nadería en la medida en que no se la puede vincular a nada, ya que nunca entró en el sistema de la simbolización - pero que, en determinadas condiciones, puede amenazar todo el edificio". ${ }^{4}$ Intentamos, entonces, circunscribir la pregunta que suscita en Luciano el desencadenamiento.

En tercer lugar, impulsamos al sujeto a dar algún tipo de tratamiento a los fenómenos que padece. En este sentido, Lacan (1956) plantea que, a partir del desencadenamiento, el psicótico entra a un mundo extraño donde todo se le vuelve signo, signo en tanto representa algo para él, llamado imperiosamente a leerlo. La alucinación, las voces, la intuición delirante, son fenómenos que tienen una significación, aunque el sujeto sea incapaz de precisar cuál - al menos por el momento - Aquí es donde se juega la certeza: no se trata de la certeza respecto

4. La idea de "no entrar en el sistema de la simbolización" se perfilará más adelante como forclusión de la Metáfora Paterna. 


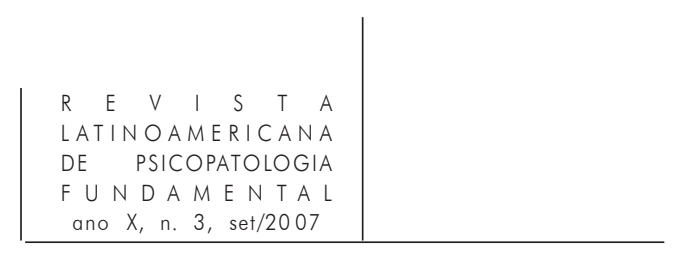

del sentido que se le da al fenómeno elemental, sino la certeza de que es su destinatario, que está completamente tomado por la experiencia. Es decir, la índole del objeto de su certeza puede ser ambigua ${ }^{5}$ - lo que deja en pie el carácter enigmático del fenómeno -; pero significa para él algo inquebrantable: eso significa y le concierne.

No obstante, consideramos este movimiento no se constata siempre espontáneamente. Luciano permanece tomado por la experiencia, pero no parece llamado a leer significación alguna en estos fenómenos que se le imponen. Al respecto, Soler (2002) destaca que la experiencia enigmática del psicótico se desdobla en dos tiempos: entre la experiencia del no sentido percibido en el primer grado y la de su conversión en certeza de significación en el segundo grado (significación plena). La autora llama "trabajo de la psicosis" al intento de darle una significación particular, un sentido, a estos retornos. Por lo tanto, si Luciano no se encuentra llamado a leer estos fenómenos, entonces esta apelación debe construirse del lado del analista.

\section{Segundo momento: constitución del delirio filiatorio. Demanda y transferencia}

En este segundo tiempo, asistimos a la constitución de un delirio filiatorio. Si bien de acuerdo al contenido ideico podría ser clasificado como delirio místico, preferimos denominarlo filiatorio para hacer énfasis en la función de esta construcción, que viene a dar cuenta de la filiación para el sujeto. ${ }^{6}$

En cuanto a la dirección de la cura, las intervenciones se orientan a lanzar preguntas que permitan organizar una trama delirante que tienda a la estabilización, lo cual sólo es posible a partir de la instalación de un lazo transferencial. Si bien en primera instancia el pedido del tratamiento es de su padre, a medida que Luciano toma la palabra comienza a dar testimonio de la experiencia que padece. Pregunta: "¿Le digo la verdad? No anote. Todo lo que le digo es confidencial Que mi papá no escuche”. Resultan interesantes estas operaciones en tanto podemos leer en ellas un atisbo de descompletamiento del Otro persecutorio: algo

5. Sauvagnat (1997) destaca que ya Clemens Neisser (1892) señala este fenómeno, que denomina "significación personal", y al cual describe como la contradicción entre la certeza del paciente de ser designado y la incertidumbre completa en lo concerniente al sentido de tal designación.

6. David Kreszes (2000) asevera que todo delirio tiene una intención filiatoria en tanto asume una función restitutiva de la significación fálica no producida. En este sentido, señala la función "ordálica" que Freud adscribe al delirio schreberiano. 


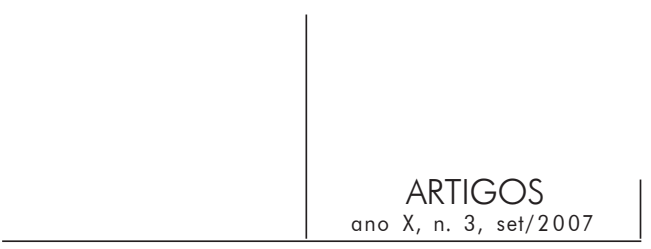

puede sustraerse al saber del Otro, algo puede devenir un secreto, hay algo que el sujeto puede poner en reserva. "Doctora: me gusta ese collar de corazón que tiene, parece que tiene el corazón abierto, como yo, transparente. (¿En qué te quedaste pensando?) Pensaba si usted me aguanta o no. La gente te trata bien pero no sabes lo que piensan (uno no puede saber lo que piensa el otro) Algunos sí. No cuente nada, pero mi abuela es vidente. Una vez escuché la voz de ella diciendo 'Ah, él fue', hablaba por mi mente (Él fue... qué?) El que había derrocado a Menem". ${ }^{7}$

Como vemos, existe una demanda desde el momento en que el sujeto nos elige para confiarnos algo de su experiencia. Sin embargo, esta demanda se perfila como paradójica. Al respecto, Jean Allouch (1986), si bien plantea una diferenciación de lugares (del polo del Otro absoluto al polo del otro como semejante) en relación a la posibilidad de trabajo con un sujeto psicótico, también señala que esta demanda nos ubica en un lugar indecidible: "Discriminar estos lugares nos orienta dentro de la transferencia psicótica. No se trata del mismo destinatario cuando un psicótico nos dice como a quien lo entiende todo 'Para qué voy a hablarle, Usted está al corriente', y cuando nos hace el honor de tomarnos por testigos de su testimonio, demandándonos sancionar su validez, pero desde un sitio desde donde está excluido que podamos hacerlo". Volvamos al texto del paciente: "Me quedé frío cuando mi abuela me leyó el pensamiento. Es raro que pase eso en este mundo, es feo, te lee el sueño. Imagínese si le leyera el pensamiento, no le gustaría. No puedo, pero a través de sus ojos veo su sueño, su persona, es buena usted. Veo un ángel de ojos verdes. ¿Qué ve Ud. a través de mí? (Veo a Luciano, un hombre) No, pero a través. (Yo no veo a través) ¿No? qué raro. Deben ser dones que nos da Dios a algunos. Yo pensé que Ud podía, entonces ¿para qué le voy a contar? - se calla - (Precisamente, como no sé todo, podés contarme)".

¿Por qué calificar la demanda del psicótico como paradójica? Porque si bien debemos abstenernos de ocupar el lugar de ese Otro gozador, omnipotente (lugar ocupado por la abuela en las alucinaciones psíquicas) $;^{8}$ por otro lado, muchas veces somos convocados allí, dado que precisamente existe la necesidad de hacer consistir la alteridad, hacerla consistente. Somos invitados a ocupar el lugar de un Otro omnisciente ( "Si usted no consigue ver a través de mí, ¿para qué le voy a contar?") porque, paradójicamente, este Otro que no permite al sujeto existir

7. Presidente de la República Argentina entre 1989 y 1999.

8. Tomamos el concepto de "alucinaciones psíquicas" (o pseudoalucinaciones) del psiquiatra francés Séglas. No se trata de una voz recortada en el afuera, el pensamiento de su abuela habla en su cabeza. Ver al respecto Lanteri-Laura (1991). 


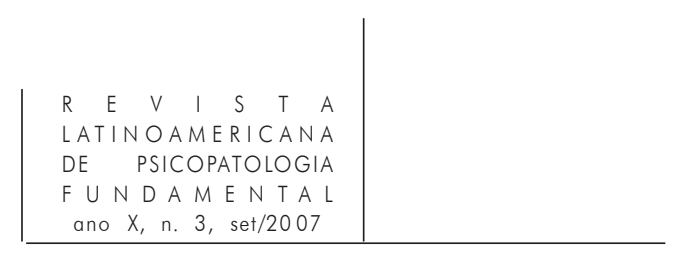

es garante de la única existencia posible. En efecto, ¿por qué la transferencia estaría exenta de esta lógica de relación - y de no relación - del psicótico con la alteridad? Michel Silvestre (1985) propone que: "Si, en su demanda inicial, el psicótico espera del analista significantes propios para organizar los trastornos de su mundo; en su demanda segunda, esa a partir de la cual la transferencia se orientará, el psicótico propone su goce al analista para que éste establezca sus reglas. Es incluso mediante ese rodeo como parece instalarse como objeto $a$ y darse, entregarse, como tal, al goce del analista". Marcel Czermak (1986) ilustra esta particularidad del trabajo con pacientes psicóticos señalando "resisten mal a la transferencia", es decir, lejos de no establecer una transferencia con el analista, el tipo de transferencia que entablan es masiva y marcadamente ambivalente. En otros términos, esta modalidad de la transferencia nos ubica permanentemente en el riesgo de la salida persecutoria (en el caso de Luciano, en relación a lo persecutorio del saber absoluto del Otro) y/o erotomaníaca. Para Luciano la transferencia parece estar cifrada en la cuestión de la transparencia, en su transparencia para el Otro (la abuela, el analista, etc). Desde luego que la abstinencia no se reduce al silencio - desde el silencio también puede situarse al sujeto como objeto de Goce -; se trata de la apuesta a ocupar el lugar de la alteridad de otro modo. Así, cuando Luciano pregunta si soy casada, le pregunto qué se imagina. Me responde: "Pienso que sí, por el tipo de collar y los aros, las mujeres casadas usan cosas así. Así es la piba que me gusta, yo le hablo y ella no me cuenta nada, se ríe de mí”. Le respondo que yo no le cuento sobre mi vida porque este espacio es para hablar de él, de lo que le pasa, de lo que piensa, de lo que siente, y para intentar ayudarlo con aquello que lo hace sufrir.

En cuanto a la conformación del delirio, reconocemos un movimiento que va desde la vivencia de fin de mundo (representada en su relato de la crisis en el gobierno del presidente De la Rúa) ${ }^{9}$ a cierta reconstrucción por la vía de su lazo filiatorio con Dios. En distintas entrevistas, me hace testigo de la constitución de su delirio. En un primer momento se refiere a la crisis política de Argentina de diciembre de 2001. "Yo lo miraba y manejaba todo. Perdí el control de mí mismo, actuaba por el televisor. (¿Qué manejabas?) El Congreso, a los hipócritas, los casos de impunidad". Su vivencia comienza a ligarse fuertemente con los significantes de la religión: los hipócritas son los que están contra Dios. En esa misma entrevista, retoma el episodio de las alucinaciones psíquicas: "Ah, me olvidaba de contarle del reloj! Ese día estaba con mi abuela, algo me controlaba, estaba yo pero me controlaba otro. El reloj se daba vuelta solo y no entendí nada.

9. Presidente de la República Argentina entre 1999 y 2001. Fue forzado a renunciar por presión popular luego de una aguda crisis económico-política. 


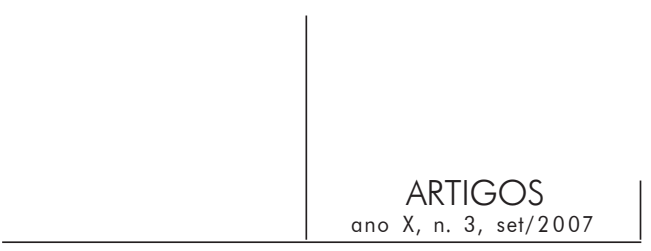

Me hizo poner nervioso. (¿Qué pensás de eso?) Creo que tiene que ver un poco con la iglesia. Todo tiene que ver con la iglesia”. El sujeto no estaba, allí estaba Otro. A partir de este Otro aplastante que no le deja espacio para existir, Luciano construye delirantemente un Otro (Dios, el Padre) que, incluso siendo potente y arbitrario, le asigna un lugar como sujeto, inscribiéndolo filiatoriamente. Este movimiento se repite en un segundo momento ${ }^{10}$ cuando historiza su vínculo con su padre real. Como dijimos, el movimiento va desde un Padre terrible, atroz, absoluto, pasando por la mención de un Padre divino que lo inscribe como hijo, hasta terminar asumiendo un padre que tiene limitaciones y del cual se puede esconder alguna cosa. Veamos tres recortes que atestiguan este pasaje:

"Le tengo miedo al agua, no sé nadar, tengo terror de caerme al mar y ahogarme. (Tu papá es marinero, no?) Sí, pero él no tiene miedo de nada. Yo soy parecido a mi papá, sólo que él es cruel y yo no. Nació así su personalidad. Que no me escuche, shh. Él hizo desaparecer las Torres Gemelas porque no obedecieron a Dios. Veíamos la tele, justo cuando se cayeron las torres. Me miraba Satanás, se reía. Eso hizo mi viejo porque la gente no hizo caso. Por televisión veo todo lo que va a pasar, desde chiquito estoy conectado con el televisor. Lo quiero tirar a la mierda, no va a estar más Satanás, no sé qué tengo en la pantalla. De chico me acuerdo que comía y miraba la tele, la imagen me absorbe y me chupa a la película...". Luciano se refiere a su infancia, y se repiten las imágenes que remiten a ahogarse, a ser chupado por, a desaparecer como sujeto. Este Padre es un padre cruel, despótico, arbitrario, pero comienza a estar presente discursivamente (a diferencia de la madre, totalmente ausente de su relato - ver infra, p. 13).

En un segundo recorte, Luciano se ubica como hijo y circunscribe un lugar narcisístico (en el sentido del narcisismo primario) de adoración. "El pastor me dijo ${ }^{11}$ 'eres el primero y el último', soy el primero, el principal. Se siente algo especial, los domingos son de adoración en la Iglesia, eso lo hacen para mí. Yo vine a la Tierra para mi reencuentro con Jesucristo, que vendría a ser mi hermano, pero yo soy el verdadero, soy el hijo de Dios, el verbo. (el hijo de...?) Soy el hijo de mi papá, pero mi papá es Dios. Jehová se llama, pero nos ponemos nombres comunes para despistar”.

Finalmente, comienza a delinear límites en la potencia del Otro: "Conocí un pibe que tenía malos pensamientos, pensaba ser superior que Dios. Eso no quiere Dios, que nadie sea superior. Dios es diferente, es bueno, pero también tiene sus límites. A veces él ve que hago cosas malas y no hace nada. Si él fuera malo me

10. Ver infra.

11. La familia de Luciano es evangélica. 


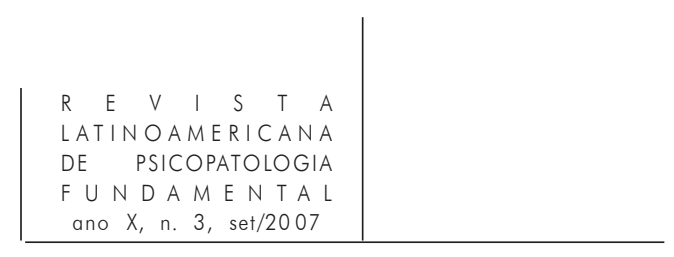

mataría. (¿) Por ejemplo, hice cosas malas con la mirada en la tele: las inundaciones, la presidencia de Menem. Esa presidencia era un momento histórico y yo lo arruiné. No sé qué tengo contra Menem, es como una obsesión. Todo Menem como si fuera Dios. Perón ${ }^{12}$ tenía algo contra él. Estoy del lado de Perón, mi abuelo era loco ${ }^{13}$ por Perón, mi papá también. Ojalá hubiese estado ahí, me hubiera gustado estar nacer en esa época”. Entonces, Dios tiene límites, no puede aplastarlo como sujeto, incluso cuando él haga cosas malas. Además de la insistencia de referentes paternos, por primera vez aparece el "como si", tomando cierta distancia de la certeza del delirio. Menem "como si fuera" Dios, pero no es. En efecto, las líneas fundamentales, los organizadores de su delirio se sitúan en relación al establecimiento de un linaje filiatorio. En este punto, la producción delirante comienza a ceder y se perfila un tercer momento en el trabajo.

\section{Tercer momento: atisbos de historización. Producción pictórica y onírica}

En lugar del delirio, Luciano me propone en primera instancia dibujar, y en segundo término, comienza a traer intensamente sus sueños a sesión.

En cuanto a sus dibujos, así como en el momento previo a través de su delirio, es posible situar la cuestión filiatoria, la inscripción de Luciano en una cadena de hombres de mar (tanto el padre como el abuelo y el tío son marineros). En los dibujos se multiplican las referencias al agua: el mar, el río, los animales acuáticos, los barcos. Algo de lo fallido aparece permanentemente: hace falta escapar, está siempre presente el peligro de ahogarse. Su primer dibujo es un barco pirata, insiste en que le falta el ancla, el nombre del barco es "Llegando a casa".

En otra sesión dibuja un pulpo. Siempre resulta dificultoso favorecer las asociaciones, en esta oportunidad plantea que los pulpos viven en el agua y tiran "un polvo negro para defenderse de los que los atacan. Tira el gas y se escapa". Ante la pregunta de quién lo ataca, dibuja un tiburón, responde: "se lo quiere comer. Ah, ayer fuimos a comer un asado a casa de mi hermana". Hacia el final de la sesión le planteo que alguna razón debe haber para que él haya dibujado esta escena, responde: "a veces me siento como un pulpo, quiero escapar de mi papá (i) no me deja salir".

12. Presidente de la República Argentina entre 1946 y 1955 y entre 1973 hasta su muerte (1974).

13. El abuelo paterno pasó el final de sus días en un psiquiátrico. Es interesante aquí el valor doble de "ser loco por algo" (apreciar mucho algo) y "ser loco por algo" en el sentido de "volverse" loco. 


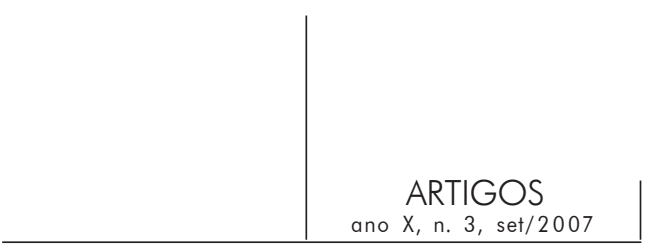

En otra ocasión dibuja una canoa, donde un amigo se va a una isla: "lo echó el papá porque se portaba mal, rompía cosas. (¿?) Estaba enojado con el papá. Yo me enojo por pavadas".

Retomamos en el curso del tratamiento la vía del enojo en relación al Padre. Sólo aparece espontáneamente en torno a él; las referencias a la madre siempre vienen del lado del analista. Cuando se le pregunta por su madre, las respuestas aluden a la nada: “ ¿mi mamá? Nada” "No existe”. Intento favorecer un trabajo de historización, pregunto por su infancia, dice no recordar nada. Sólo aparecen dos recuerdos, ligados a cierta inscripción del Otro primordial, en relación a la función materna: "Mi mamá está en mi casa, no quiere comer, no quiere hacer nada, se la pasa durmiendo y cuando hace algo, compra cigarrillos. Es como si no estuviera (¿desde cuándo?) Desde siempre. De chico me pegaba. Estaba en la mesa y me rompió la nariz, tenía 10 años (¿) no sé por qué... estaba jugando (se queda callado, le pregunto "en qué pensás?”) ¿quién? (vos). Estoy tratando de acomodarlo. Siempre me trataba así. Y mi papá... en el barco”.

Más allá de la presencia o ausencia física del padre, pareciera no haber operado una inscripción de la función paterna, en tanto limitación del deseo materno. En otro recuerdo, la figura de la hermana condensa significaciones ligadas a una función de cuidados, posiblemente como figura que lo salvó de ahogarse en el deseo (o no deseo) materno. "No me acuerdo mucho. Siempre íbamos a la piscina, un día casi me ahogo. Mi hermana más grande me sacó de un pie, yo tenía la cabeza en el agua y me sacó para que no me ahogue". De hecho, esta hermana parece haberse ocupado de él de niño, ya que su madre estaba permanentemente internada y su padre embarcado.

En las asociaciones ligadas a este recuerdo se abre una vía muy interesante en relación a su historia y al desencadenamiento. Cuando le pregunto si frecuentemente iban a la piscina me responde: "Sí, los siete". Indago quiénes son los "los siete", ya que ellos son seis de familia. Me corrige "En verdad somos siete. Tenía otro hermano que nació y lo abortaron. (¿?) No sé nada, era el mayor. Me contó mi papá el año pasado y me puso mal, eran pobres, se ve que no tenían nada para comer". En otra sesión, añade: “me deprimí por eso, perder un hermano es triste, no?".

Trabajamos entonces en torno al desencadenamiento. Es posible situar que el año pasado fue fundamental: la caída de De la Rúa, se "deprimió" por enterarse de la pérdida de su hermano, dejó el colegio, comenzó a sentirse mal... le pregunto si se le ocurre algo más. Responde: “Mi hermana mayor tuvo un bebé, pensé que iba a ser un nene, era una nena. Me agarró el mal de ojo, debe ser el diablo, no sé”. Como vemos, en la reconstrucción de la historia del desencadenamiento, aparecen como contemporáneos dos acontecimientos que se condensan en la caída de un referente paterno (el presidente). Por un lado, la noticia de la existencia de 


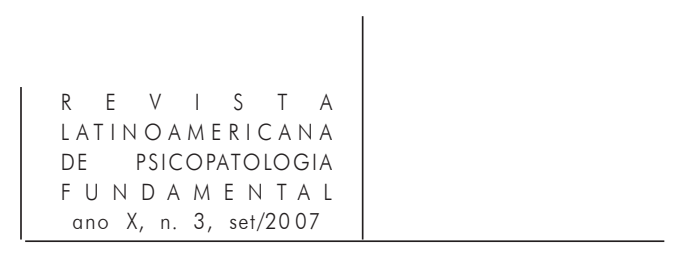

un primer eslabón de esta cadena fraterna, abortado. Notemos el estatuto paradójico de la aserción: "nació y lo abortaron". "Es triste perder un hermano", un hermano que nunca había existido (para él hasta el momento), pero el saber de su existencia lo inscribe como perdido. En segundo lugar, el nacimiento de una hija de su hermana mayor. ¿Qué cimientos subjetivos fundamentales ponen en juego este nacimiento y esta muerte?

Posteriormente, comienza a tener un mayor peso el proceso de construcción de lo paterno y lo filiatorio: construcción de un Padre potente, interdictor, omnisciente, seductor, poseedor de todas las mujeres. Pero esta vez no se trata de Dios, se trata de su padre. "Mi papá se hace el lindo, el misterioso, cuando habla de los barcos. Se hace como que sabe todo (¿eso te molesta?) sí, porque entonces yo no sé nada. Dice que lo buscan las mujeres, le dice a mi mamá que es más joven que ella. Debe ser verdad. Yo lo vi con una rubia, yo tenía 12 o 13 años, y era la fiesta de un diputado. A mí antes me daban bolilla las mujeres, ahora no. No salgo. Yo nunca me subí a un barco (no hace falta ser marinero para ser hombre)".

Paralelamente a estos movimientos se hace evidente un fortalecimiento de los lazos sociales. Vuelve a salir con amigos, si bien se queja de ciertas desigualdades y diferencias. Por ejemplo, le molesta mucho no poder jugar al truco. ${ }^{14}$ En una sesión en la que me propone jugar constato que conoce las reglas, pero le resulta imposible lidiar con la posibilidad de engañar o ser engañado.

Dice que le gustaría salir más de noche pero que el padre quiere que esté mejor para poder salir. En este sentido es interesante la primera aparición del padre como garante de cuidados: "Mi viejo me dijo que no, dijo que por ahora no, hasta que esté mejor. No se embarcó esta vez porque le preocupaba mi salud".

Finalmente, Luciano comienza a traer sus sueños a sesión. En general, se trata de escenas congeladas, en las que pueden leerse ciertos ejes fundamentales, ligados al trabajo de análisis, pero a partir de los cuales difícilmente se abren asociaciones. Incluso me pregunto qué estatuto tienen estas producciones y si se trata de sueños en sentido estricto. Algunas de estas imágenes parecen ser calcadas de sus alucinaciones, aunque esta vez aparecen en su relato como sueños, en un registro totalmente diferente. "Estaba en una cueva y nacía un bebé y después otro, y después otro y no lo vi y después se terminó el sueño. Los sacaban de la panza". En otra sesión: "Soñé que un tipo decía 'yo soy dios', un barbudo de blanco (¿) Nada, dijo eso nomás, ese pedacito nada más soñé. El tipo era barbudo, de pelo negro y barba negra (parecido a alguien?) Tenía la cara de mi papá. Yo me reía, le decía que él no era Dios!”.

14. Juego de naipes tradicional en Argentina, para el cual "el mentir" es una habilidad fundamental. 


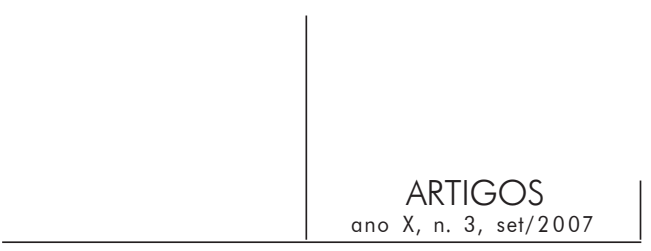

Nótese el movimiento de basculación entre una figura de la alteridad omnipotente (su padre como Dios destruyendo las Torres Gemelas) y una figura de poder desdibujada, irrisoria. Si bien resulta difícil trabajar los sueños a partir de asociaciones está claro que estos sueños vienen a poner en escena cuestiones fundamentales como el sexo, el nacimiento, la figura del Otro y su posición como sujeto. En otras ocasiones los sueños aparecen ligados a restos diurnos y en este sentido se perfila cierto acceso a un movimiento de historización. "Doctora, anoche tuve una pesadilla. Había una señora desnuda y un hombre desnudo, y otros dos teniendo relaciones, eran unos bolivianos: el padre con la madre. (¿Los dos que tenían relaciones quiénes eran?) No sé. Ah sí!! Mi hermana más chica, Nora. - se ríe - Se estaban bañando en la pileta y ella tenía relaciones. Yo miraba... el sueño fue mío (¿y vos que sentías?) miedo. Me asustaban los otros, desnudos y gordos, hablaban y no entendía nada (y lo de Nora, qué pensás de eso?) Ella tiene novio, pero no sé. Tenía una foto de él y mi papá se la sacó y ella se puso a llorar, yo me reía. (...)Yo tengo que tener relaciones sexuales".

Durante las asociaciones, comenta que un vecino le sugirió salir con una prostituta, que los amigos lo molestan, le dicen que su acné se debe a la falta de sexo y que seguramente él es gay. Dice que, si bien le parece que los amigos se lo dicen en broma, a él le molesta profundamente. Relata un episodio de una supuesta relación sexual con un compañero en un campamento. El acontecimiento y el relato son muy confusos, cuesta precisar el momento $(12,13$ años) y lo que sucedió: "yo no me dejé”... "tuvimos relaciones pero no lo besaba". Continúa hablando de los amigos, y dice que ellos también "se mandan macanas". Cuando se le pregunta qué tipo de macanas, dice que a veces se acuestan con las hermanas, o con otros hombres. Con cierta indiferencia, cuenta que se acostó con su hermana mayor, le cuesta precisar hace cuántos años, pero cree que fue entre los 12 y los 14 años, luego se desdice, cree que tenía 10. Insiste en que fue idea de ella, que ella lo llamó, pero que el padre no se puede enterar porque lo mataría. Trabajamos más en torno de este recuerdo, que no vuelve a traer a sesión. Evidentemente es difícil establecer la veracidad del acontecimiento, aunque de cualquier modo sabemos que esta escena (recuerdo o fantasía) es eficaz psíquicamente. El sueño da pistas fundamentales porque liga el incesto (su hermana menor teniendo relaciones en el sueño, su hermana mayor teniendo relaciones con él en el recuerdo) al horror (se trata de una pesadilla). La supuesta escena incestuosa revela su lugar de objetalización, objeto del exceso de quien tenía a cargo la función materna.

Luciano continúa su trabajo y se produce un cierto movimiento de estabilización, que le permite comenzar a pensar acerca de su futuro, tener algunas relaciones sociales y empezar a trabajar como aprendiz en una fábrica. 


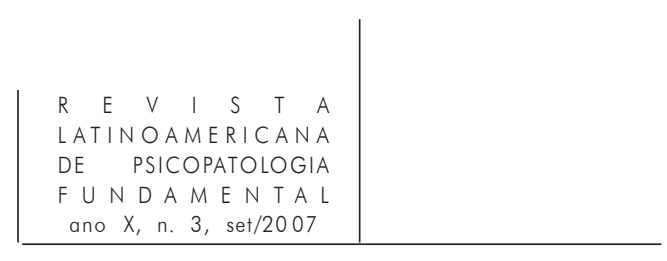

\section{Consideraciones finales}

El desencadenamiento en la psicosis es una contingencia que pone en juego y revela la operatoria fallida en la constitución subjetiva. Para Luciano se trata de los estragos que ocasiona la irrupción de acontecimientos ligados al sexo, la muerte, la procreación y lo incestuoso. ¿La maternidad de su hermana - la cual cumple una función materna en su historia y con la que dice mantener un vínculo incestuoso - pone en juego psíquicamente la paternidad para Luciano? ¿Qué lugar tienen en esta coyuntura el nacimiento/muerte del hermano mayor? Parece existir una colisión de dos acontecimientos: el nacimiento de su sobrino (¿hijo?) y el dicho que trae a la existencia de palabra la muerte del primogénito. Luciano da cuenta de esta colisión y del derrumbe consecuente en la paradoja de la afirmación: "nació y lo abortaron".

Efectivamente, el desencadenamiento sitúa lo bizarro del deseo del Otro. En las escenas en que Luciano habla del sexo, ante el intento de armado del analista, predomina la sensación de lo borroso, lo que no se puede terminar de saber (fechas, sucesos). Luciano parece subsumido a la palabra del Otro ("dicen que soy gay"); lo único que se recorta de la nebulosa de la incertidumbre es esta posición de Luciano como objeto "de", sea en una relación homo o heterosexual ("no me dejé", "se le ocurrió a mi hermana"). Hay imposibilidad de reglar el encuentro con lo sexual, lo cual habla de una función fálica que no opera, y que revela como trasfondo la relación incestuosa. En efecto, lo que lo enloquece, lo patógeno, es la emergencia del Otro gozador, correlativa a la falta de inscripción de la función paterna. Su Otro primordial aparece como incestuoso; la abuela presentifica esta cara de la alteridad en el fenómeno de la alucinación psíquica. Efectivamente, este fenómeno elemental ilustra notablemente esta particular dimensión de la alteridad en la psicosis. La voz no se recorta en el afuera sino que parasita su cabeza; es una voz interior, pero no es la voz del superyo estructurado simbólicamente. Por el contrario, es un interior ajeno, donde se juega la certeza. No hay voz que interpele al sujeto en el sentido del llamado, no se trata de una interpelación sino de un imperativo que aplasta al sujeto. Petrificación del sujeto, que parece no poder replicar, ni confrontar, ni siquiera aceptar: debe ser.

En este sentido, es notable su posición de inocencia: la dimensión de la culpabilidad, que en la neurosis nos permite seguirle la pista al deseo inconciente, le es ajena. No hay indicios de asunción de culpa o vergüenza en relación a su destrucción del país o en su relato de las escenas incestuosas. El superyo no se constituye aquí como "éxtimo" (Lacan, 1960) - exterior e íntimo al mismo tiempo - , sino que se hace presente en lo real a través de la injuria. No hay punto de vacilación sino certeza inmediata: él es el referido. "Ah, es él": interrupción de la 


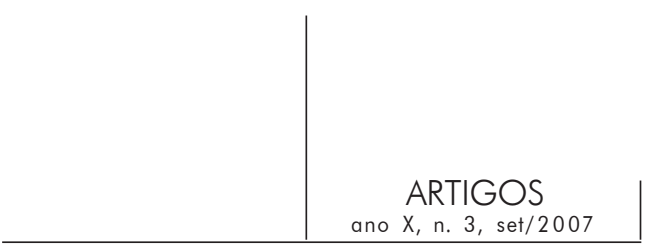

frase. En el momento de la pregunta del analista se da el movimiento de la producción delirante: "él es quien bajó a Menem". Frente al momento de perplejidad de la alucinación ("me quedé frío"), el completamiento de la frase continúa el trabajo de restitución de la psicosis pero deslizándose al terreno de la restitución delirante. Es decir, si bien Luciano es todavía objeto de la palabra del Otro, la producción delirante sitúa al sujeto de otro modo. Jean Allouch (1986) considera que: "Es primeramente en el lugar del Otro donde el sujeto psicótico es tomado. Este hecho masivo, decisivo, no será absorbido por el delirio, aunque aún en ciertas condiciones, el delirio permita al sujeto asumir esta nominación". De hecho, el trabajo del delirio - y en este sentido puede pensarse como filiatorio o restitutivo de la significación fálica -, sitúa al mismo tiempo un Dios todopoderoso que lo elige e inscribe en su linaje y un Dios irrisorio e impotente. Doble vertiente que, a la vez que hace consistir al Otro, le da cierto margen de existencia al sujeto: "Eso no quiere Dios, que nadie sea superior. Él es diferente, es bueno pero también tiene sus límites". En este punto podemos localizar la pregunta por la estabilización: la metáfora delirante sitúa un Padre que ordena el campo del Goce y ubica al sujeto en una cadena filiatoria. A partir de este momento, se favorece un impulso a la historización en el cual el sujeto parece querer construir algo de lo paterno reproduciendo este doble movimiento de adjudicarle absoluta potencia y al mismo tiempo hacerlo irrisorio, ${ }^{15}$ reconstruyendo a su vez los enigmas de su historia.

\section{Referencias}

Allouch, Jean. Vous êtes au courant. Il y a un transfert psychotique. Revue Littoral. Paris: EPEL, n. 21, 1986, p. 89-110.

Breuer, Josef y Freud, Sigmund (1893-1895). Estudios sobre la histeria. In: Obras Completas. Buenos Aires: Amorrortu, 1996. v. II.

Czermak, Marcel. Passions de l'Objet. Études psychanalytiques des psychoses. Paris: Clims, 1986.

Kreszes, David (org.). Superyo y filiación. Destinos de la transmisión. Rosario: Laborde, 2000.

15. La figura del Otro como irrisorio aparece claramente en el sueño en el que se ríe de aquel hombre con barba (nótese que su padre tiene barba), diciéndole que no puede ser Dios. 


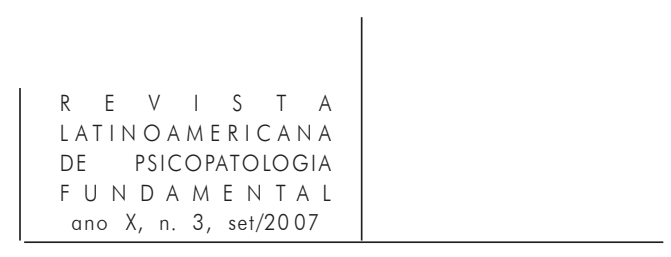

Freud, Sigmund (1911). Sobre un caso de paranoia descrito autobiográficamente. In: Obras Completas. Buenos Aires: Amorrortu, 1996. v. XII.

(1924). Neurosis y psicosis y La pérdida de realidad en la neurosis y la psicosis. In: Obras Completas. Buenos Aires: Amorrortu, 1993. v. XIX.

LaCAN, Jacques (1956). Le séminaire. Livre III. Les psychoses. Paris: Seuil, 1981.

(1958). D'une question préliminaire à tout traitement possible de la psychose. In: Écrits. Paris: Seuil, 1966.

(1960). Le séminaire. Livre VII. L'étique de la psychanalyse. Paris: Seuil, 1986.

Lanteri-Laura, Georges. Les Hallucinations. Paris: Masson, 1991.

Sauvagnat, François. Phénomènes élémentaires psychotiques et travail institutionnel. Cahier de l'ACF-VLB. n. 8, 1997, p. 101-17.

Silvestre, Michel. Transferencia e interpretación en las psicosis. Una cuestión de técnica. In: Psicosis y psicoanálisis. Buenos Aires: Manantial, 1985. p. 31-8.

SOLER, Colette. L'inconscient à ciel ouvert de la psychose. Paris: Mirail, 2002.

\section{Resumen}

Este trabalho propõe algumas considerações sobre a especificidade da demanda e da transferência na psicose. Para ilustrar as reflexões teóricas, apresenta-se um fragmento de um caso clínico, dividido em três momentos fundamentais que revelam diferentes modalidades de funcionamento psíquico. Inicialmente, predominam as alucinações e as vivências de fragmentação, cuja significação permanece enigmática. Posteriormente, o paciente estrutura um delírio místico em relação a sua filiação simbólica. Em um terceiro momento, analisam-se as produções pictóricas e oníricas, o qual permite ao sujeito um movimento de historicidade e certa estabilização.

Palavras-chave: Demanda, transferência, psicose, alucinação, delírio

Cet article aborde conceptuellement la spécificité de la demande et le transfert dans la psychose. Il présente des réflexions théoriques à partir d'un fragment d'un cas clinique divisé en trois moments fondamentaux, issus de modalités de fonctionnement psychique différentes. En premier lieu, les hallucinations, les expériences de fragmentation et de vide, dont le sens reste énigmatique, prédominent. Ensuite, le patient structure un délire mystique qui rend compte de sa filiation symbolique. Finalement, il analyse les productions picturales et oniriques qui permettent au sujet d'atteindre un mouvement d'historisation, ainsi qu'une certaine stabilisation.

Mots clés: Demande, transfert, psychose, hallucination, délire 


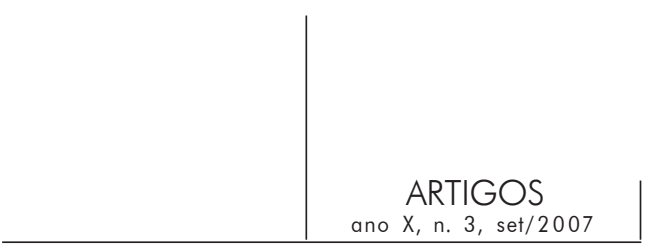

This article examines specific aspects of demand and transference in psychosis. The conceptual reflections are presented in connection with a case, is divided into three distinct moments, according to different psychical functions. Initially, the patient has hallucinations and experiences fragmentation, and their meanings remain enigmatic. With time, the patient is able to structure a mystical delirium that symbolizes his filiation. Finally, analysis of his or her drawings and dreams allows the thrapist to deal with his history and allows some level of stabilization.

Key words: Demand, transference, psychosis, hallucination, delirium

Versão inicial recebida em novembro de 2006

Versão revisada recebida em junho de 2007 